\title{
Routine Offered Protocol is not reliable for Thrombophlebitis Prevention
}

\author{
Habib Yaribeygi ${ }^{1}$, Mohammad Javad Hosseini ${ }^{2}$, , Hamid Rokhsarizadeh ${ }^{3}$, Gholam Hossein Meftahi ${ }^{1}$, Mahmoud Salesi ${ }^{4}$ \\ ${ }^{1}$ Neuroscience Research Center, Baqiyatallah University of Medical Sciences, Tehran, IR Iran \\ ${ }^{2}$ Molecular Biology Research Center, Baqiyatallah University of Medical Sciences, Tehran, IR Iran \\ ${ }^{3}$ Baqiyatallah University of Medical Sciences, Tehran, IR Iran \\ ${ }^{4}$ Research Center for Prevention of Oral and Dental Diseases, Baqiyatallah University of Medical Sciences, Tehran, IR Iran
}

*Corresponding Author: Mohammad Javad Hosseini, MD, Associate Professor, Molecular Biology Research Center, Baqiyatallah University of Medical Science, Vanak square, Mollasadra Street, Tehran, Iran. Tel: +98-02181263618, Email: dr_mjhosseini@yahoo.com

Received: 24 Dec. 2015; Accepted: 16 Feb. 2016; Online Published: 28 May. 2016

\begin{abstract}
Background: Intravenous catheterization is a routine technique in medical centers which can cause diverse problems such as thrombophlebitis.

Objective: This study aimed to resolve replacement scheduling and proper cannula diameter and position issues for intravenous catheters.

Methods: In this 2015 experimental cohort study, 232 hospitalized patients receiving medication intravenously were assessed for the occurrence of thrombophlebitis (TF). Involved TF factors such as age, gender, cannula size, site of cannula in hand veins, duration of usage, and underlying disease were evaluated in patient and healthy control groups.

Results: TF developed in 55 of 232 patients. The percentages of incidence were similar in men and women (30\%). The patient mean age was lower than that of the control, but the difference was not significant. Average weight was significantly higher in the patient group than in the control group. The average duration of cannula in situ was significantly lower in patients than in the control group. The highest rate of TF occurred in the narrowest cannula usage and dorsal hand vein positions. The mean time of developing TF was lower than that indicated in CDC guidelines. Furthermore, 24 patients with TF (34\%) had diabetes mellitus.

Conclusion: In the current study, the percentage of TF occurrence was higher in patients with weight increase, use of narrower cannulae, dorsal hand vein positions, and a history of diabetes. Furthermore, TF can develop within 72 hours. It was concluded that some patients may be more susceptible to TF and require more care. Accordingly, the CDC guidelines' offered scheduling for intravenous catheter replacement is not trustworthy.
\end{abstract}

Keywords: Thrombophlebitis, Cannula, Risk Factors, Patients, Hospitals

\section{Background}

Intravenous catheterization is a routine technique for delivering medication which is required by up to $70 \%$ of hospitalized patients [1], but it can lead to clinical problems [2]. Thrombophlebitis (TF) - inflammation of the catheterized vein - is one of these problems [2, 3]. Its incidence rates vary widely from $5.3 \%$ [4] to $77.5 \%$ of all inserted catheters [5], 27 cases per 100 subjects. or 104 cases per 1000 catheter days [6]. TF can be caused by mechanical, chemical, or infectious factors at the traumatized branch of the vein around the point of intravenous catheter insertion [7].

There is a huge body of literature about TF, but unfortunately there are no standard markers or criteria for its diagnosis [8]. It is usually identified by such markers as redness, warming, swelling, inflammation, erythema, pain, hardening along the vein, and cord-like veins [9]. Based on its symptoms, a phlebitis scale was developed by the Infusion Nurses Society. According to it, TF is graded into six different categories [7]. TF may occur because of patient-related reasons (e.g., sepsis) or economic origins (e.g., extra nursing workload) [9, 10]. This clinical complication can impose large costs on medical and health managing systems worldwide [2]. Moreover, there is some association between TF and several other disorders such as deep vein thrombosis (DVT) [11], pulmonary embolism [12], and even cancers [13, 14]. Therefore, the prevention or early diagnosis and treatment of TF are very important issues [2].

There is some controversy among studies of TF. It has been reported that $\mathrm{TF}$ occurrence is higher in some veins and positions and is also higher in females than in males [3]. Cicolini et al. reported a higher prevalence of TF in female patients than in male and proposed some safer veins (especially cubital fossa veins) for cannula insertion [15]. They also stated that small sizes of cannula can reduce TF incidence [15]. In contrast, Myrianthefs reported a higher rate of $\mathrm{TF}$ with cannulae with a lesser diameter [16]. In another study, no relation between gender and $\mathrm{TF}$ was reported [17]; however, Lundgren et al. reported a higher incidence of TF in males [18]. Higginson proposed that inappropriate sites for PVCs (peripheral vein catheters) can increase the incidence of TF [7], but Lee et al. showed that the cannula insertion site is not an independent risk factor for TF [10].

There are some instructions for cannula replacement and length of time for cannula in situ. Some, like CDC 2002, believe that replacing catheters every 72-96 hours (known as the routine replacement method) is a safe protective procedure for reducing TF incidence [19]. Other evidence, however, contradicts this idea. For example, Grüne et al. (2003) and Myrianthefs (2005) reported that routine replacement is not protective for $\mathrm{TF}$ and patients require daily monitoring $[6,20]$. The CDC 2011 guidelines have 
labelled the catheter replacement method as an unresolved matter which needs more investigation [21].

\section{Objective}

The aim of the current study was to achieve a better understanding of superficial TF risk factors, compare them between patients and healthy subjects, and evaluate whether or not the routine replacement method can prevent TF.

\section{Methods}

This observational-comparative cohort survey was carried out in 2015 on 232 patients in two separate groups (patient and control) at an Iranian hospital located in Tehran. The subjects were randomly sampled based on inclusion and exclusion criteria. Inclusion criteria were no fatal underlying disease such as cancer, hepatitis, etc. and no translocation to another care ward. Exclusion criteria were discharge before 72 hours of cannula insertion (in patients with no TF), receipt of specific drugs (such as immunosuppressant), and presence of other vascular problems such as cellulite. Considering these criteria, 11 patients were excluded from the study.

All patients had PVCs for medication of four common sizes: 16, 18, 20, and 22 gauge. The catheters were inserted in four routine sites: dorsal hand, forearm, elbow veins, and arm veins. Only one PVC per subject was observed and evaluated in this study. The patients were regularly examined by a specialist (2nd author) for TF. Diagnoses were made by detecting main TF markers such as erythema, pain, swelling, warming, and redness along the vein using the checklist by Lundgren et al. (1993). Major TF risk factors identified in previous studies, including age, gender, weight, site of cannula, size of cannula, duration of cannula in situ, and underlying disease, were assessed. As soon as $\mathrm{TF}$ was detected in a patient, the catheter was removed and necessary nursing interventions were performed. Then, the aforementioned risk factors in $\mathrm{TF}$ patients and control subjects were compared. All patients were cared for in one clinical part of the hospital (general surgery), received similar medications, and had similar nursing staffs.

Quantitative data regarding frequency, percentile, and mean \pm SE was analyzed. Differences between the two groups were assessed using one-way ANOVA and the chisquare tests. All statistical analyses were performed by means of the SPSS $^{\circledR}$ Advanced Statistical ${ }^{\mathrm{TM}} 16$ software package.

This research conforms to the ethical guidelines of the World Medical Association Declaration of Helsinki, 2008). Moreover, all patients gave consent to participate, and local ethical rules were fully considered.

\section{Results}

This study evaluated a total of 232 patients, of which 93 subjects $(\sim 40 \%)$ were female and $139(\sim 60 \%)$ were male. The age of participants ranged from 13 to 93 years (mean age $=56.5 \pm 17.03$ ). A total of 70 patients_developed $\mathrm{TF}$ $(30.1 \%)$, of which 28 subjects were female and 42 were male (Table 1). The prevalence was similar between men and women $(30 \%)$. The average age of patients with TF was $57.44 \pm 2.64$ years, which was insignificantly lower than that of the control $(55.46 \pm 1.94)$. The mean weight of the patients was $73.89 \pm 1.56 \mathrm{Kg}$, which was significantly higher than the control group $(67.88 \pm 1.39 \mathrm{~kg})(\mathrm{p}<0.01)$. The mean duration of cannula remaining in situ was $49.5 \pm 3.16$ hours in patients with $\mathrm{TF}$, a significantly lower time than in the control group $(72 \pm 0.00$ hours $)(\mathrm{p}<0.05)$. Moreover, 24 patients with TF $(34 \%)$ had diabetes mellitus; this number was significantly higher than that of the control group $(\mathrm{p}<0.05)$ (Table 2).

\begin{tabular}{lccc}
\multicolumn{4}{c}{ Table 1. TF prevalence data } \\
\hline Variable & Overall & Control & Patient \\
\hline Male & $139(60 \%)$ & $97(70 \%)$ & $42(30 \%)$ \\
Female & $93(40 \%)$ & $65(70 \%)$ & $28(30 \%)$ \\
Total & $\mathbf{2 3 2}(\mathbf{1 0 0 \% )}$ & $\mathbf{1 6 2}(\mathbf{6 9 . 8 \%})$ & $\mathbf{7 0}(\mathbf{3 0 . 1 \%})$ \\
\hline
\end{tabular}

\begin{tabular}{lccc}
\multicolumn{4}{c}{ Table 2. Comparison of risk factors between groups } \\
\hline Variable & Control & Patient & P value \\
\hline Age (years) & $55.46 \pm 1.94$ & $57.44 \pm 2.64$ & 0.05 \\
Weight (kg) & $67.88 \pm 1.39$ & $73.89 \pm 1.56$ & 0.05 \\
Cannula in situ (hours) & $72.0 \pm 0.00$ & $49.5 \pm 3.16$ & 0.05 \\
\hline All p values were 0.05 & & &
\end{tabular}

The PVCs assessed numbered 23 (10\%) 16 gauge, 70 (30\%) 18 gauge, $104(\sim 45 \%) 20$ gauge, and $35(15 \%) 22$ gauge. The highest rate of TF $(15$ cases $=43 \%$ of 35$)$ occurred with the narrowest PVCs (22 gauge), followed by $35 \%$ (37 cases) with 20 gauge, $20 \%$ (14 cases) with 18 gauge, and $17 \%$ (4 cases) with 16 gauge (Table 3). All differences were statistically significant $(\mathrm{P}<0.025)$.

Table 3. Cannula size and TF prevalence

\begin{tabular}{lccc}
\hline Cannula Size & Number & With TF (\%) & P value \\
\hline 16 gauge & 23 & $4(17 \%)$ & 0.025 \\
18 gauge & 70 & $14(20 \%)$ & 0.025 \\
20 gauge & 104 & $37(35 \%)$ & 0.025 \\
22 gauge & 35 & $15(43 \%)$ & 0.025 \\
Total & $\mathbf{2 3 2}$ & $\mathbf{7 0}(\mathbf{3 0 \%})$ & $\mathbf{0 . 0 2 5}$ \\
\hline
\end{tabular}

All p-values were 0.025

The highest rate of phlebitis occurred in dorsal hand veins $(41 \%)$ and was significantly higher than other PVC sites $(\mathrm{P}<0.000)$ (Table 4).

Table 4. Cannula locations in hand veins

\begin{tabular}{lccc}
\hline Location & Number & With TF & P value \\
\hline Dorsal hand veins & $78(33.6 \%)$ & $32(41 \%)$ & 0.000 \\
Forearm veins & $57(24.56 \%)$ & $9(15.7 \%)$ & 0.000 \\
Cubital fossa veins & $65(28.01 \%)$ & $20(30.7 \%)$ & 0.000 \\
Arm veins & $32(13.79 \%)$ & $9(28.1 \%)$ & 0.000 \\
Total & $\mathbf{2 3 2 ( 1 0 0 \% )}$ & $\mathbf{7 0}(\mathbf{1 0 0 \%})$ & $\mathbf{0 . 0 0 0}$ \\
\hline
\end{tabular}

All p-values were 0.00

\section{Discussion}

It appears that a series of factors are involved in TF in hospitalized patients [7, 20]. In the current study, no differences were observed in statistics between men and women and prevalence was similar between the two sexes. Furthermore, the average ages of patients and healthy subjects were not significantly different. The differences in mean body weight were significant, however, and thus, incidence of TF may be higher in patients with a higher body weight $[9,22]$.

A higher incidence of TF in dorsal hand veins was observed, which is consistent with previous studies [15]. Therefore, the insertion of cannula in an appropriate vein may reduce the risk of $\operatorname{TF}[9,23]$. It is likely that the increased risk of TF in dorsal hand veins occurred because of the flexibility of the joints, which may increase the risk of mechanical contact between the vessel wall and the tip of the inserted cannula [24]. The results of this study are consistent with those of Cicollini et al., who proposed forearm veins as a cannulation location safe from TF [23]. Another factor was the diameter of the cannula. Its role was confirmed in the present study; a cannula with a smaller 
diameter (22 gauge) produced a higher risk for TF. Cicolini et al. (2009) stated, however, that smaller catheter size can reduce the risk of TF and concluded that the higher rate of endothelial injury induced by the size of the catheter may create greater exposure of patients to TF [15]. However, there is some controversy about this result. Uslusoy et al. (2008) reported similar risks of TF from using varying sizes of cannulae; it could be from their study conditions [17]. Karadag and Gorgulu also reported similar risks of TF occurring with 18- and 20-gauge cannulae [25]. Conversely, Macklin (2003) and Tagalakis (2002) reported that small catheters reduce the risk of TF, because they allow better blood flow in neighboring tissues and thus avoid injury to the vein's intima $[9,24]$. The higher risk of TF from small catheters in the present study may have been caused by the greater irritation of intima by mobile narrow cannulae or possibly from the quick release of drugs into the veins.

There are two usual methods for clinically indicated or routine replacement for intravenous catheterization [26]. Nonetheless, there is no agreement about which is preferred. Maki (2013) reported that these two methods did not differ for TF [27]. Wu and Casella (2013) also indicated that routine replacement has no proven advantage [28]. Likewise, Rickard et al. (2012) showed that PVCs can be removed as clinically indicated, which will prevent millions of catheterizations and is associated with more comfort for patients, lower costs, and reduced staff workload [26]. Based on the 2001 guidelines of the CDC (Center for Disease Control and Prevention), Iranian hospitals use intravenous injective catheters for a maximum duration of 72 hours. In most studies, TF occurred after 72 hours. In the current study, TF occurred within about 50 hours after insertion and spurred a debate. This showed that TF can develop in lesser time than mentioned in the CDC guidelines, and if the routine replacement technique is applied every 72 hours, the risk of TF can rise. Therefore, it is proposed that close continuous observation of patients must remain with prompt removal of complicated cannulae [26].

\section{Conclusion}

It can be concluded that some patients are more susceptible to TF and may develop it within less than 72 hours after cannula insertion. This "tendency for phlebitis" may result from having simultaneous multiple risk factors, such as higher body weight, underlying disease (such as diabetes mellitus), and/or a history of TF. Thus, routinely elective replacement of cannula every 72 hours is not a reliable preventive method for TF. This study offers that, in addition to regular replacement of catheters in all patients, vulnerable subjects must be recognized quickly and given more care for TF than others.

\section{Acknowledgments}

The authors would like to thank the "Clinical Research Development Unit" of Baqiyatallah Hospital for their kind cooperation. They also appreciate the kind cooperation of the dear patients.

\section{Authors' Contributions}

MJH developed the original idea and supervised the research. HY developed the protocol, collected the data, and wrote the manuscript. HR and MS contributed by analyzing data. GHM edited the final manuscript.

\section{Conflict of Interest}

This study had no conflict of interest.

\section{References}

1. Zingg W, Imhof A, Maggiorini M, Stocker R, Keller E, Ruef C. Impact of a prevention strategy targeting hand hygiene and catheter care on the incidence of catheter-related bloodstream infections*. Crit Care Med. 2009;37(7):2167-73. [DOI]

2. Dychter SS, Gold DA, Carson D, Haller M. Intravenous therapy: a review of complications and economic considerations of peripheral access. J Infus Nurs. 2012;35(2):84-91. [DOI]

3. Di Nisio M, Peinemann F, Porreca E, Rutjes AW. Treatment for superficial infusion thrombophlebitis of the upper extremity. Cochrane Database Syst Rev. 2015;11:CD011015. [DOI]

4. Curran E, Coia J, Gilmour H, McNamee S, Hood J. Multi-centre research surveillance project to reduce infections/phlebitis associated with peripheral vascular catheters. J Hosp Infect. 2000;46(3):194-202. [DOI]

5. Lundgren A, Wahren LK, Ek A-C. Peripheral intravenous lines: time in situ related to complications. J Infus Nurs. 1996;19(5):22938

6. Grüne F, Schrappe M, Basten J, Wenchel H, Tual E, Stützer H. Phlebitis rate and time kinetics of short peripheral intravenous catheters. Infection. 2004;32(1):30-2. [DOI]

7. Higginson R PA. Phlebitis: treatment, care and prevention, a review. NursTime. 2011;107(36):4.

8. Ray-Barruel G, Polit DF, Murfield JE, Rickard CM. Infusion phlebitis assessment measures: a systematic review. J Eval Clin Pract. 2014;20(2):191-202. [DOI]

9. Tagalakis V, Kahn SR, Libman M, Blostein M. The epidemiology of peripheral vein infusion thrombophlebitis: a critical review. Am J Med. 2002;113(2):146-51. [DOI]

10. Lee W-L, Chen H-L, Tsai T-Y, Lai I-C, Chang W-C, Huang C-H, et al. Risk factors for peripheral intravenous catheter infection in hospitalized patients: a prospective study of 3165 patients. Am J Infect Control. 2009;37(8):683-6. [DOI]

11. Jorgensen J, Hanel K, Morgan A, Hunt J. The incidence of deep venous thrombosis in patients with superficial thrombophlebitis of the lower limbs. J Vasc Surg. 1993;18(1):70-3. [DOI]

12. Noël-Savina E, Paleiron N, Le Gal G, Descourt R. [Septic pulmonary embolism after removal of a venous access device for septic thrombophlebitis]. J Mal Vasc. 2012;37(3):146-9. [DOI]

13. Mouton, Kienle, Muggli, Naef, Wagner. Tumors associated with superficial thrombophlebitis. Vasa. 2009;38(2):167-70. [DOI]

14. Diaconu C, Mateescu D, Bălăceanu A, Marcu M, Jianu V, Stănică A. Pancreatic cancer presenting with paraneoplastic thrombophlebitis-case report. J Med Life. 2010;3(1):96.

15. Cicolini G, Bonghi AP, Di Labio L, Di Mascio R. Position of peripheral venous cannulae and the incidence of thrombophlebitis: an observational study. J Adv Nurs. 2009;65(6):1268-73. [DOI]

16. Myrianthefs P, Sifaki M, Samara I, Baltopoulos G. The epidemiology of peripheral vein complications: evaluation of the efficiency of differing methods for the maintenance of catheter patency and thrombophlebitis prevention. $\mathrm{J}$ Eval Clin Pract. 2005;11(1):85-9. [DOI]

17. Uslusoy E, Mete S. Predisposing factors to phlebitis in patients with peripheral intravenous catheters: a descriptive study. J Am Acad Nurse Pract. 2008;20(4):172-80. [DOI]

18. Lundgren A, Jorfeldt L, Ek AC. The care and handling of peripheral intravenous cannulae on 60 surgery and internal medicine patients: an observation study. J Adv Nurs. 1993;18(6):963-71. [DOI]

19. O'Grady NP, Alexander M, Dellinger EP, Gerberding JL, Heard SO, Maki DG, et al. Guidelines for the prevention of intravascular catheter-related infections. Clin Infect Dis. 2002;35(11):1281-307. [DOI]

20. Myrianthefs P, Karatzas S, Baltopoulos G. Complications, thrombophlebitis rates, and intravenous catheter replacement strategies. Infection. 2005;33(2):96-7. [DOI]

21. O'Grady NP, Alexander M, Burns LA, Dellinger EP, Garland J, Heard SO, et al. Guidelines for the prevention of intravascular catheter-related infections. Am J Infect Control. 2011;39(4):S1-S34. [DOI]

22. Gaukroger P, Roberts J, Manners T. Infusion thrombophlebitis: a prospective comparison of 645 Vialon and Teflon cannulae in anaesthetic and postoperative use. Anaesth Intensive Care. 1988;16(3):265-71.

23. Cicolini G, Manzoli L, Simonetti V, Flacco ME, Comparcini D, Capasso L, et al. Phlebitis risk varies by peripheral venous catheter site and increases after 96 hours: a large multi-centre prospective study. J Adv Nurs. 2014;70(11):2539-49. [DOI] 
24. Macklin D. Phlebitis: A painful complication of peripheral IV catheterization that may be prevented. Am J Nurs. 2003;103(2):5560. [DOI]

25. Karadag A, Görgülü S. Effect of two different short peripheral catheter materials on phlebitis development. $J$ Infus Nurs. 2000;23(3):158-66

26. Rickard CM, Webster J, Wallis MC, Marsh N, McGrail MR, French $\mathrm{V}$, et al. Routine versus clinically indicated replacement of peripheral intravenous catheters: a randomised controlled equivalence trial. Lancet. 2012;380(9847):1066-74. [DOI]

27. Maki DG. ACP Journal Club. Clinically indicated and routine replacement of peripheral IV catheters did not differ for phlebitis. Ann Intern Med. 2013;158(2):JC8. [DOI]

28. Wu MA, Casella F. Is clinically indicated replacement of periphera catheters as safe as routine replacement in preventing phlebitis and other complications? Intern Emerg Med. 2013;8(5):443-4. [DOI] 